\title{
MICELLAR ENHANCED SYNCHRONOUS FLUORESCENCE FOR THE ASSAY OF SUMATRIPTAN SUCCINATE IN PHARMACEUTICAL TABLETS
}

\author{
SAFWAN M. FRAIHAT \\ Department of Chemistry, Faculty of Science, The University of Jordan 11942, Amman-Jordan \\ Email: s.fraihat@ju.edu.jo
}

Received: 03 Dec 2018, Revised and Accepted: 12 Feb 2019

\begin{abstract}
Objective: To develop a sensitive, fast and selective method for the determination of sumatriptan succinate (SUM) in pharmaceutical samples.

Methods: The method is based on measuring the synchronous fluorescence of SUM using $\Delta \lambda$ of (12 $0 \mathrm{~nm})$ and at a wavelength of excitation and emission of 230 and $325 \mathrm{~nm}$ respectively, using Agilent Technology, Cary eclipse, G9800AA model Luminescence spectrometer. Effect of variables on fluorescence emission intensities was studied such as solvent, surfactant, and $\mathrm{pH}$. The proposed method was validated in term of linearity, limit of detection as per the international conference on harmonization guidelines ICH Q2 (R1).
\end{abstract}

Results: The linearity of the method was obtained with a wide range of (50-150) ng/ml with a high value of correlation coefficient value of (0.992). Limits of detection (LOD) and limits of quantitation (LOQ) were found to be 16.3 and $49.5 \mathrm{ng} / \mathrm{ml}$ respectively, the mean recovery was found to be 99.1\% with low relative standard deviation (\% RSD). The method was also compared statistically with the reference method using t-test and f-test, the results show no difference either in pure or pharmaceutical tablets.

Conclusion: The obtained results revealed that the developed method can be applied successfully for the determination of SUM in drug formulations samples with good accuracy and precision.

Keywords: Sumatriptan, Spectrofluorimetry, Pharmaceutical preparations

(C) 2019 The Authors. Published by Innovare Academic Sciences Pvt Ltd. This is an open access article under the CC BY license (http://creativecommons.org/licenses/by/4.0/) DOI: http://dx.doi.org/10.22159/ijap.2019v11i2.31118

\section{INTRODUCTION}

Triptans are used for the treatment of prophyllaxis and acute migraine headaches in human, the most commonly used drug among triptans is sumatriptan succinate (fig. 1) it is chemically 3-[2-(diaminoethyl)]-Nmethyl-indole-5-methane sulfonamide succinate. sumatriptan is a specific and selective 5-hydroxyl tryptan receptor (5HT1D) agonist with no effect on other 5HT receptor (5HT2-5HT7) subtypes.

It is official in European pharmacopeia [1] and United States pharmacopeia [2].

Several methods were suggested for the determination of sumatriptan in different types of samples, including, UV [3], spectrophotometric [4-6], other methods were based on highperformance liquid chromatography with various detecting systems such as UV detection [7], fluorescence detection [8] and MS detection $[9,10]$. Other methods were based on and voltammetry [11]. Few methods were based on the fabrication of nanomaterialbased sensing methods [12-14]. According to the previous methods, it can be seen that most of them are based on using expensive and sophisticated techniques, this encourages us to develop a simple method for the assay of sumatriptan in the pharmaceutical samples. Spectrophotometric methods are widely used in the pharmaceutical analysis, but they have poor selectivity and sensitivity compared to spectrofluorimetry $[15,16]$. The developed method is based on the enhancement of the intrinsic Fluorescence of SUM, then measuring Synchronous Fluorescence intensities in different media. All the factors affecting the fluorescence intensities were studied, including the type of solvent, $\mathrm{pH}$, temperature and micellar additives. The developed methods were validated and applied to real pharmaceutical samples and were compared with official methods. Synchronous fluorescence technique has many priorities compared to conventional fluorescence spectroscopy, including simple spectra, higher selectivity, sensitivity and lower interferences which are due to sharper and narrower fluorescence peaks [17-19]. It is well known that the presence of surfactants may increase the rigidity of the molecules being surrounded by the surfactant which restricts the movement of the fluorophore and so decrease the energy transfer to the surrounding environment, As a result, increases the quantum yield and enhance the fluorescence intensity of the guest molecules $[21,23]$. The anionic surfactant sodium lauryl sulfate (SLS) has recently found many applications in emission fluorescence enhancement and applications for the determination of some pharmaceutical compounds [24].

The developed method is considered as a low cost, a time-saving and sensitive method that has the advantages of not using derivatization reactions using toxic chemicals. Moreover, another method of the conventional spectrofluorimetric technique was applied using the synchronous scanning fluorescence at $(\Delta \lambda=120 \mathrm{~nm})$, which allowed a simpler spectrum with less overlapping [24].

The developed method was validated and applied successfully for the quantitative determination of (SUM) in pharmaceutical samples.<smiles>CNS(=O)(=O)Cc1ccc2[nH]cc(CCN(C)C)c2c1</smiles>

Fig. 1: Chemical structure of sumatriptan succinate

\section{MATERIALS AND METHODS}

\section{Apparatus}

Fluorescence intensities were measured using Agilent Technology, Cary eclipse, G9800AA model Luminescence spectrometer (Australia) equipped with a xenon arc lamp, The slit width for excitation and emission measurements were set at $5.0 \mathrm{~nm}$ and measured simultaneously with a constant $\Delta \lambda \operatorname{scan}\left(\lambda_{\text {emi }}-\lambda_{\text {exi }}\right)$ of 120 nm. A $1.0 \mathrm{~cm}$ quartz cell was used at $25.0{ }^{\circ} \mathrm{C}$. A pH meter (HANNA model: HI 2211) was used for all $\mathrm{pH}$ measurements. 


\section{Materials and reagents}

Reagents used were of analytical grade and deionized water was used throughout. Pure grade sumatriptan succinate were kindly supplied from Egyptian company. The pharmaceutical preparations were purchased from local drug stores oratab ${ }^{\circledR} 100 \mathrm{mg}$ tablet Tabouk company-Saudi Arabia. Sodium lauryl sulfate (SLS) $96 \%$, Tween 80, $\beta$-cyclodextrin, glacial Acetic acid were from BDH laboratory supplies, sodium acetate, sulphuric acid. Analytical grade solvents: acetonitrile 99.5\%, methanol 99.9\% dioxan 99\% were obtained from Sharlau-Spain.

\section{Standard solution}

Stock solution of SUM was prepared by dissolving $0.01 \mathrm{~g}$ in $100 \mathrm{ml}$ deionized water, then further dilutions were prepared using the given diluting solvents as appropriate and kept in the refrigerator.

\section{General procedures}

\section{Calibration graphs}

Aliquots of SUM standard solution were transferred into a series of $10-\mathrm{ml}$ calibrated volumetric flasks, then $1 \mathrm{ml}$ of $0.2 \mathrm{M}$ acetic acid/acetate buffer of $\mathrm{pH}(5.5)$ was added, followed by $0.5 \mathrm{ml} 2 \%$ SLS, mixed and then diluted to the mark using methanol as a diluting solvent to give a final concentration of $(50-150 \mathrm{ng} / \mathrm{ml})$. Then stored in the refrigerator at $10{ }^{\circ} \mathrm{C}$ for $15 \mathrm{~min}$, after that the Fluorescence intensity was measured at appropriate excitation and emission wavelengths corresponding to the selected diluting solvent. The calibration curves were constructed by plotting the fluorescence intensity versus SUM concentration $(\mathrm{ng} / \mathrm{ml})$ and the regression equations were obtained.

\section{Analysis of tablet samples}

The contents of ten tablets were crushed and powdered, then a mass equivalent to $10.0 \mathrm{mg}$ was weighed and transferred into a $100 \mathrm{ml}$ volumetric flask, about $75 \mathrm{ml}$ of methanol was added, the mixture was sonicated for $10 \mathrm{~min}$, then the volume is completed to $100 \mathrm{ml}$ with methanol, mixed and filtered through a $0.45 \mu \mathrm{m}$ membrane filter. Serial dilutions covering the working concentration range of $(50-150 \mathrm{ng} / \mathrm{ml})$ were transferred into a series of $10.0 \mathrm{ml}$ volumetric flasks. Then the procedure mentioned in the preparation of calibration graph was followed.

\section{RESULTS AND DISCUSSION}

Spectrofluorimetic methods of analysis are considered as sensitive and simple for the determination of many pharmaceutical active species in different samples $[25,26]$. To our knowledge there is no analytical method based on native fluorescence of SUM, in this study, it was found that SUM exhibits an emission fluorescence spectrum at about $350 \mathrm{~nm}$ after excitation at $225 \mathrm{~nm}$ in aqueous medium (fig. 2) So there is a need to investigate the effect of different media on such behavior, because of its relatively low relative fluorescence intensity (RFI). It is important to develop a simple and sensitive spectrofluorimetric method for the determination of SUM in a different type of samples. In this study, various experimental factors that influence the RFI of SUM were studied in order to decrease the detection limit. So different factors were studied as follow:

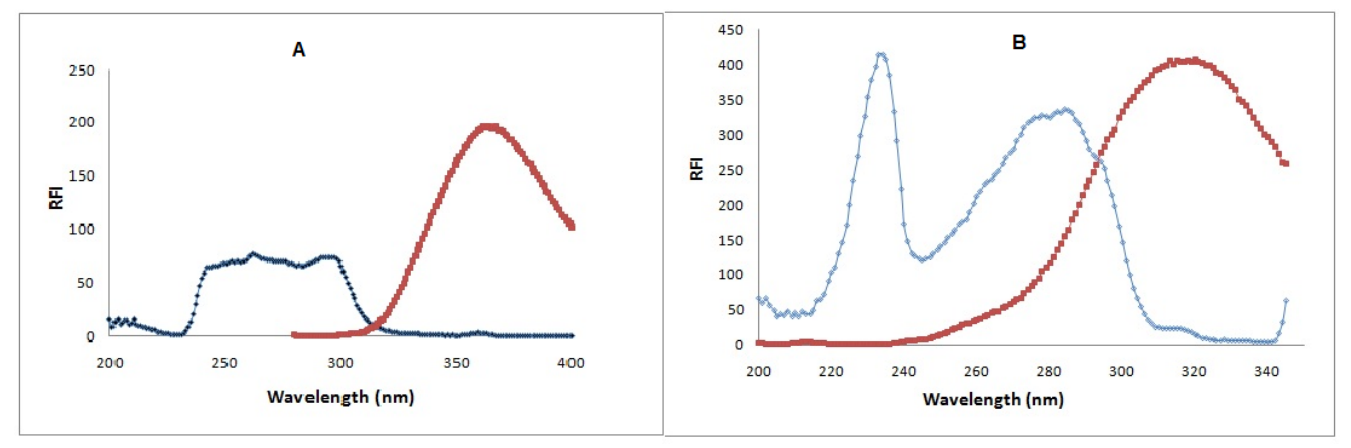

Fig. 2: Fluorescence spectra of SUM $(100 \mathrm{ng} / \mathrm{ml})$ in $10.0 \mathrm{ml}$ of water (A) and methanol (B)

\section{Effect of diluting solvent}

In order to study the effect of different media on the enhancement of fluorescence intensity, different organic solvents were used as diluting solvents including acetonitrile, methanol, ethanol, and dioxan. It was found that the fluorescence intensity is enhanced with the order of methanol, acetonitrile, dioxan and then ethanol as can be seen in (fig. 3). This behavior is probably due to the dynamic stabilization of the studied drug. The emission wavelengths of SUM in dioxan were 275 and 350 for acetonitrile and $294 \mathrm{~nm}$ for methanol. The excitation wavelength were 298, $262 \mathrm{~nm}$ and $253 \mathrm{~nm}$ of the three solvents respectively.

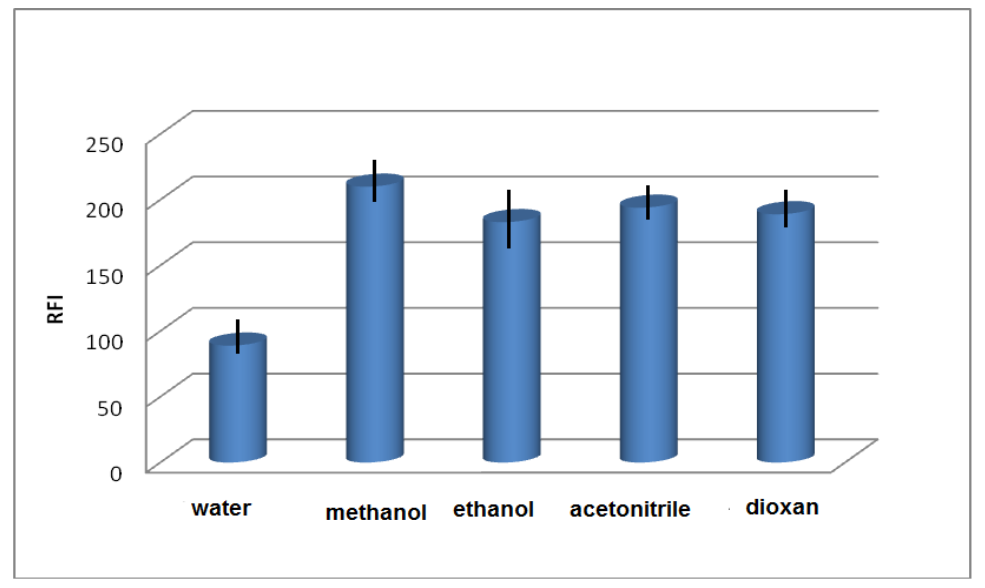

Fig. 3: Effect of diluting solvent on RFI of $10.0 \mathrm{ml}$ solution of SUM $(100 \mathrm{ng} / \mathrm{ml})$, error bars represent the standard deviation of three experiments 


\section{Effect of organized media}

For the better enhancement of the analytical characteristics of the fluorescence spectra of SUM, a study of the effect of different types of surfactants (cationic, anionic and nonionic) and beta-cyclodextrin was performed using the different effect of equal volume each surfactant used were summarized in (fig. 4), it can be shown that SLS gave the best enhancement of the RFI which is due to the dynamic properties of limited movement of the micellar medium of SUM [25].

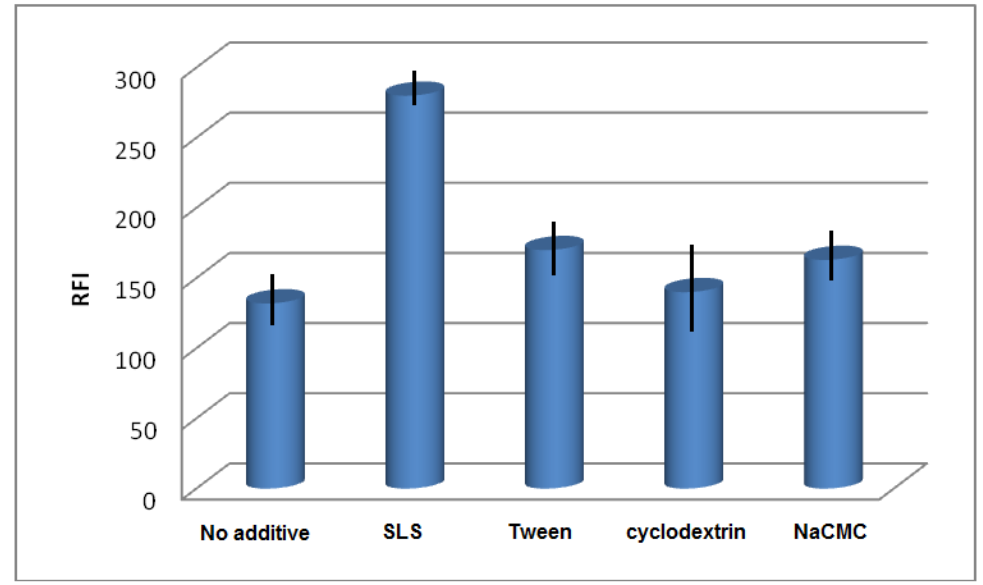

Fig. 4: Effect of the addition of organized media on RFI of SUM (100 ng/ml), $10.0 \mathrm{ml}$ sample, after the addition of $1 \mathrm{ml}$ of $0.5 \%$ of each medium of the RFI of SUM. Error bars represent the standard deviation of three experiments

\section{Effect of $\mathrm{pH}$}

The effect of $\mathrm{pH}$ values on the fluorescence intensity was studied by using different values of $\mathrm{pH}$ prepared by different buffer solutions with methanol as a diluting solvent and SLS surfactant, it was found that the maximum value of fluorescence intensity was obtained at $\mathrm{pH}$ around 5 using acetate buffer as shown in (fig. 5), which is probably due to the formation of a non-ionizable form of the studied drug at this $\mathrm{pH}$ value.

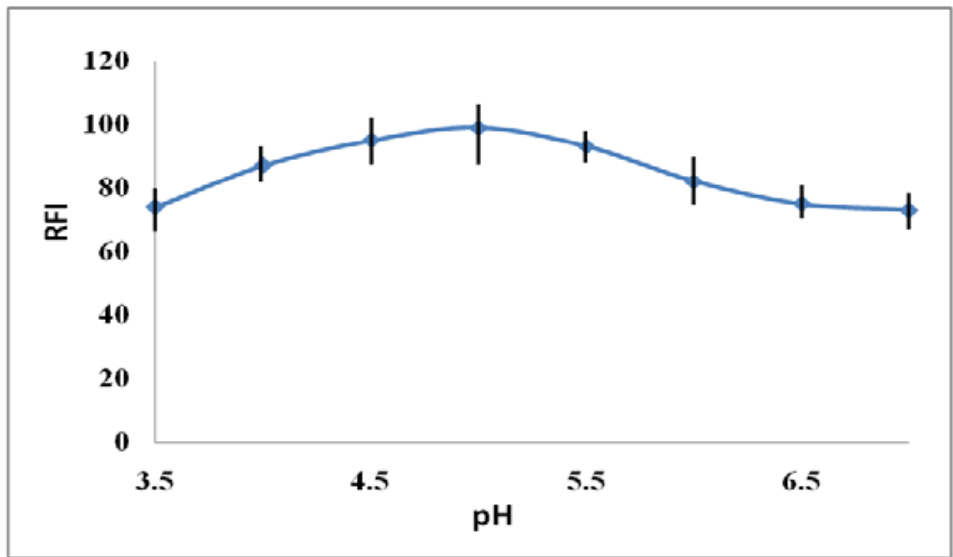

Fig. 5: Effect of pH on RFI of SUM (100 ng/ml) using acetate buffer, error bars represent the standard deviation of three experiments

In order to minimize the broadening of the emission fluorescence peaks and thus possible overlapping and minimize scattering. An alternative method for the conventional fluorescence spectrum is the use of synchronous scanning fluorescence. In this technique, the excitation and emission monochromator were scanned simultaneously and the emission intensity is recorded as a function of the excitation wavelengths. The difference between $\lambda_{\mathrm{em} .}$ and $\lambda_{\mathrm{ex}}$ $(\Delta \lambda)$ is a very important factor in the synchronous spectrum for determining the position of the bands and their intensities. In the present work the optimization of $\Delta \lambda$ ) was performed by selecting different values of $\Delta \lambda$ ) then interpretation of the fluorescence spectrum, as a resul $\Delta \lambda=120 \mathrm{~nm}$ was selected because it gave sharper peak with maximum intensity, least peak overlap and increase in (RFI) as a function of concentration of SUM as shown in (fig. 6) below.

\section{Validation of the proposed method}

The developed method was validated using the following parameters: Linearity, sensitivity, LOD, LOQ, specificity, accuracy and precision.

\section{Linearity and range}

A linear relationship was established for SUM by plotting relative fluorescence intensities against different drug concentrations, the calibration curve was linear over the range $50-150 \mathrm{ng} / \mathrm{ml}$ with a high value of correlation coefficient $(r)$ table 1. 




Fig. 6: Calibration of SUM using the proposed synchronous method using, $(\Delta \lambda=120 \mathrm{~nm})$ in methanol with SLS added, the concentration range is $(50-150 \mathrm{ng} / \mathrm{ml})$

\section{Limit of detection (LOD) and limit of Quantitation (LOQ)}

LOD and LOQ were calculated according to ICH Q2 (R $\left.{ }_{1}\right)$ recommendations [ICH Expert Working Group. ICH harmonized tripartite guidelines. Validation of Analytical procedures: text and methodology [28], using the following equations and the results are shown in table 1

$$
\begin{aligned}
\mathrm{LOD} & =3.3 \mathrm{Sa} / \mathrm{b} \\
\mathrm{LOD} & =10 \mathrm{Sa} / \mathrm{b}
\end{aligned}
$$

Where Sa: standard deviation of the intercept and Sb: standard deviation of the slope of the calibration curve.

Validation of the developed spectrofluorimetric methods

Table 1: Analytical Performance data of the proposed method

\begin{tabular}{ll}
\hline Parameter & SUM \\
\hline Synchronous scanning range (nm) & $200-300$ \\
$\Delta \lambda(\mathrm{nm})$ & 120 \\
Linearity range $(\mathrm{ng} / \mathrm{ml})$ & $50-150$ \\
Correlation coefficient & 0.992 \\
Slope (b) & 0.939 \\
Intercept (a) & 68.4 \\
SD of the intercept (Sa) & 4.65 \\
SD of the slope (Sb) & 0.0021 \\
$\% \mathrm{RSD}^{\mathrm{a}}$ & 1.3 \\
$\mathrm{LOD}^{\mathrm{b}}(\mathrm{ng} / \mathrm{ml})$ & 16.3 \\
$\mathrm{LOQ}^{\mathrm{c}}(\mathrm{ng} / \mathrm{ml})$ & 49.5 \\
\hline
\end{tabular}

aPercent relative standard deviation of three replicate samples, bLimit of detection, cLimit of quantitation

\section{Accuracy and precision}

To investigate the accuracy and precision of the developed method, the assay results of SUM were compared from standard reference method [28], statistical analysis of the results using student's t-test and variance ratio $F$-test [30] showed no significant differences between the performance of the proposed method and reference method regarding accuracy and precision (table 2)

\begin{tabular}{|c|c|c|c|c|c|c|}
\hline \multirow[t]{2}{*}{ Parameter: } & \multicolumn{2}{|c|}{ Proposed method } & \multirow[t]{4}{*}{ \% Found } & \multicolumn{2}{|c|}{ Reference method } & \multirow[t]{4}{*}{$\%$ Found } \\
\hline & Amount & Amount & & Amount & Amount & \\
\hline & taken & found & & taken & found & \\
\hline & $(\mathrm{ng} / \mathrm{ml})$ & $(\mathrm{ng} / \mathrm{ml})$ & & (ng/ml) & $(\mathrm{ng} / \mathrm{ml})$ & \\
\hline & 5.0 & 4.974 & 99.48 & 5.0 & 4.910 & 99.20 \\
\hline & 10.0 & 9.876 & 98.60 & 10.0 & 10.074 & 100.27 \\
\hline & 20.0 & 20.143 & 100.7 & 20.0 & 19.948 & 99.74 \\
\hline & 50.0 & 49.651 & 99.30 & 50.0 & 50.204 & 100.41 \\
\hline$* \overline{\mathrm{x}} \pm \mathrm{SD}$ & & & $99.52 \pm 0.87$ & & & $99.82 \pm 0.61$ \\
\hline t-value & 0.32 & & & & & \\
\hline F-value & 0.57 & & & & & \\
\hline Oratab $^{\circledR}$ & & & & & & \\
\hline $100 \mathrm{mg}$ tablet & 20.0 & 19.93 & 99.6 & 20.0 & 20.07 & 100.4 \\
\hline & 40.0 & 39.76 & 99.4 & 40.0 & 39.89 & 99.7 \\
\hline & 60.0 & 58.85 & 98.3 & 60.0 & 59.87 & 99.8 \\
\hline $\begin{array}{l}{ }^{*} \bar{x} \pm S D \\
\text { t-value } 0.065(3.18) \\
\text { F-value } 0.450(9.55)\end{array}$ & & & $99.1 \pm 0.7$ & & & $99.9 \pm 0.38$ \\
\hline
\end{tabular}

Table 2: Assay results of the proposed method for SUM in pure and tablet forms compared with a reference method

${ }^{*}$ mean $\pm \mathrm{SD}$, (SD)-standard deviation, $\mathrm{n}=3$, Numbers in the parentheses are the critical tabulated values of $\mathrm{t}$ and $\mathrm{F}$ at $(\mathrm{P}=0.05)$ 
Table 3: Intra-assay and inter-assay precision and accuracy of the determination of SUM in tablets using the proposed method

\begin{tabular}{|c|c|c|c|c|c|}
\hline \multicolumn{3}{|l|}{ Intra-assay } & \multicolumn{3}{|c|}{ Inter-assay } \\
\hline Nominal conc & Measured conc. & Recovery conc & Nominal & Measured conc. & Recovery $^{a}$ \\
\hline (ng/ml) & $(\mathrm{ng} / \mathrm{ml})$ & $(\% \pm \mathrm{RSD})$ & (ng/ml) & $(\mathrm{ng} / \mathrm{ml})$ & $(\% \pm \mathrm{RSD})$ \\
\hline 50 & 50.23 & 100.5 & 50 & 49.65 & 99.3 \\
\hline 100 & 99.68 & 99.7 & 100 & 97.86 & 97.9 \\
\hline 150 & 149.57 & 99.7 & 150 & 147.83 & 98.6 \\
\hline \multicolumn{6}{|c|}{ aMean of three determinations } \\
\hline \multicolumn{2}{|l|}{$\overline{\mathrm{x}} \pm \mathrm{SD}$} & \multicolumn{2}{|c|}{$99.9 \pm 0.46$} & \multicolumn{2}{|c|}{$98.6 \pm 0.7$} \\
\hline
\end{tabular}

\section{Pharmaceutical applications}

The developed method was successfully applied for the intra-day and inter-day determining (SUM) in its drug tablets on three successive days, the recovery results were obtained for the assay of SUM in pharmaceutical tablets as shown in (table 3). The results were comparable with those obtained from the reference method.

\section{CONCLUSION}

In this study, a new nonexpensive and sensitive procedure was developed for the determination of sumatriptan succinate based on the enhancement of native fluorescence of the studied drug using methanol as solvent and sodium lauryl sulfate as a micellar medium. The new method utilized the use of synchronous scanning for the determination of SUM in both pharmaceutical tablets, the method was validated and compared with reference methods.

\section{AUTHORS CONTRIBUTIONS}

All the authors have contributed equally

\section{CONFLICTS OF INTERESTS}

\section{Declared none}

\section{REFERENCES}

1. EP. European Pharmacopoeia. Vol. 2. 6th edition; 2008. p. 3005.

2. USP. The United States Pharmacopoeia. 31 st Revision, US Pharmacopoeia Convention Inc. Rockville, MD; 2008. p. 3310.

3. Pourmand MR, Azar MS, Aghavalijamaat M. Development of validated UV spectrophotometric methods for in vitro analysis of sumatriptan in pharmaceutical preparations in comparison with HPLC. Pharm Chem J 2011;44:585-9.

4. Nair GS, Jaivik VS, Priyanka AS. Spectrophotometric determination of five commercial drugs in pure form and pharmaceutical formulations by ion-pair complexation with alizarin red s. Eur J Anal Chem 2015;10:68-83.

5. Kudige N, Kanakapura B, Madihalli S. Utilization of $\mathrm{N}$ bromosuccinimide as a brominating agent for the determination of sumatriptan succinate in bulk drug and tablets. Int J Anal Chem 2013;2013:1-11. Doi:10.1155/2013/934357

6. Nair G, Jaivik V, Priyanka A, Mallika S, Pranav S. Extractive spectrophotometric determination of five selected drugs by ion-pair complex formation with bromothymol blue in pure form and pharmaceutical preparations. Cog Chem 2015;1:1-14.

7. Femenia Font A, Merino V, Rodilla V, Lopez Castellano A. High performance liquid chromatographic determination of sumatriptan after in vitro transdermal diffusion studies. J Pharm Biomed Anal 2005;37:621-6.

8. Ge Z, Tessier E, Neirinck L, Zue Z. High performance liquid chromatographic method for the determination of sumatriptan with fluorescence detection in human plasma. J Chromatogr B: Anal Technol Biomed Life Sci 2004;806:299-303.

9. Cheng KN, Redrup MJ, Barrow A, Williams PM. Validation of a liquid chromatographic tandem mass spectrometric method for the determination of sumatriptan in human biological fluids. J Pharm Biomed Anal 1998;17:399-408.

10. Seo JJ, Park J, Bae MH, Lim MS, Seong SJ, Lee J, et al. Rapid determination of Sumatriptan in human plasma by ultra performance liquid chromatography-tandem mass spectrometry and its application to clinical pharmacokinetic study. J chromatogr B: Anal Technol Biomed Life Sci 2013;919:38-42.
11. Kamal S, Jose M, Fernandez A, Chi H, Malcolm R, Ray M. Differential pulse voltammetric determination of sumatriptan succinate $(1: 1)$ in a tablet dosage form. J Pharm Biomed Anal 1992;10:17-21.

12. Karuna A, Kiran R, Suresh K. One-pot synthesis of gold nanoparticles by using 4 -aminoantipyrine as a novel reducing and capping agent for simultaneous colorimetric sensing of four triptan-family drugs. Anal Methods 2014;6:5972-80.

13. Gholivand MB, Leila MB. Fabrication of a highly sensitive sumatriptan sensor based on ultrasonic-electrodeposition of Pt nanoparticles on the $\mathrm{ZrO}_{2}$ nanoparticles modified carbon paste electrode. J Electroanal Chem 2014;712:33-9.

14. Mandana A, Zohreh P, Abolfazl Be, Saeed Sh. Electrocatalytic determination of sumatriptan on the surface of carbon-paste electrode modified with a composite of cobalt/Schiff-base complex and carbon nanotube. J Fluoresc 2012;22:1407-13.

15. Kalyana RB, Raghubabu K. Extractive visible spectrophotometric determination of rampiril in pharmaceutical preperations. Asian J Pharm Clin Res 2011;4:82-5.

16. Manish K, Ajay K, Ram S, Jain C. Development of Uv spectrophotometric mrthof for the determination og Brnidipine hydrochloride by design (QbD) approach. Int J Appl Pharm 2018;10:92-97.

17. Hadir MM. Simultaneous determination of naproxen and diflunisal using synchronous, luminescence spectrometry. J Fluoresc 2008;18:909-17.

18. Ibrahim F, El-Enany N, Shalan SH, Abo Shabana RA. Secondderivative synchronous spectrofluorimetric determination of nebivolol hydrochloride and amlodipine besylate in their combined dosage form. Luminescence 2015;30:1011-9.

19. Yang HM, Wang YS, Li JH, Li GR, Wang Y, Tan $\mathrm{X}$, et al. Synchronous fluorescence determination of urinary 1hydroxypyrene, beta-naphthol and 9-hydroxyphenanthrene based on the sensitizing effect of beta-cyclodextrin. Bioelectrochemistry 2011;81:81-5.

20. El-Anany N, Belal F, El-Shabrawy Y, Rizk M. Second derivative synchronous fluorescence spectroscopy for the simultaneous determination of chlorzoxazone and ibrofen in pharmaceutical preparations and biological fluids. Int J Biomed Sci 2009;5:136-45.

21. Walash MI, Gelal F, Tolba MM, Halawa ML. Micelle-enhanced spectrofluorimetric determination of amlexanox in bioadhenive buccal tablets. application to content uniformity testing. Luminescence 2015;30:823-9.

22. Darwish HW, Bakheit AH. Micellar enhanced synchronous spectrofluorimetric method for determination of dasatinib in tablets, human plasma and urine: application to in vitro drug release and content uniformity test. RSD Adv 2015;5:54471-80.

23. Alarfaj NA, El-Tohamy MF. Determination of the anti-viral drug Ribavirin in dosage forms via micelle-enhanced spectrofluorimetric method. Luminescence 2103;28:190-4.

24. Belal F, Sharaf M, Tolba M, Alaa H. Micelle-enhanced spectrofluorimetric method for determination of lacidipine in tablet form; application to content uniformity testing. Luminescence 2015;30:805-11.

25. Ramadan A, Adel Marzouk, Reda A. Specific stability indicating spectrofluorimetric method for determination of ledipasvir in the presence of its confirmed degradation products; application in human plasma. Spectrochim Acta A 2018;202:50-7.

26. Abu El-Enin M, Mohammad H, El-Sharbiny D, El-Wasseef D, El-Ashry S. Validated spectrofluorimetric method for 
determination of two phosphodiesterase inhibitors tadalafil and vardenafil in pharmaceutical preparations and spiked human plasma. Luminescence 2016;31:173-8.

27. Leung R, Shah DO. Dynamic properties of micellar solutions: I. Effects of short chain alcohols and polymers on micellar stability. J Colloid Interfac Sci 1986;113:484-99.
28. Q2(R1); 2005. Available from: http://www.ich.org/lOB/ MEDIA417.pdf. [Last accessed on 01 Nov 2018]

29. Badwe N, Sharma N, Agarwal N. HPLC method for the determination of sumatriptan. East Pharmacist 1997;XL:121-2.

30. JN Miller, JC Miller. Statistics and chemometrics for analytical chemistry. $5^{\text {th }}$ ed. Prentice Hall, Uper Sddl River, NJ; 2005. 